\title{
Language as resource: a key notion for understanding the complexity of mathematics learning
}

\author{
Núria Planas ${ }^{1,2}$ (D) \\ Published online: 28 March 2018 \\ (C) The Author(s) 2018
}

\begin{abstract}
The thinking of language as resource in mathematics education research has been more metaphorical than conceptual so far. This article provides grounds and reasons for the theorization of language as resource. Based on views from sociolinguistics and functional grammar, I propose a theorization that considers the social languages of learners and the systems of language as discursive dialectical sites of potential/actual and shared/non-shared meaning production. I illustrate the analysis of a text of a student group work in order to inform the discussion. The approach to data analysis seeks out tensions between potentially realizable and actual meaning in the immediacy of situations embedded in cultures of school mathematics and the official language of instruction. In the midst of social and personal relationships and diverse experiences in/of the world, language is a shifting resource for the communication of tensions regarding languages of learners and the creation of newer situations toward the production of meaning taken as mathematical and shared.
\end{abstract}

Keywords Language $\cdot$ Discourse Culture $\cdot$ Language as resource $\cdot$ Meaning potential . Mathematics learning

\section{Introduction}

Since the 1990s and in the midst of premises regarding conceptions of language in the field, research that questions the perspective of language as problem has remained visible in several works and ways (e.g., Barwell, Chapsam, Nkambule, \& Phakeng, 2016; Ellerton \& Clarkson, 1996; Planas \& Setati, 2009; Turner, Domínguez, Maldonado, \& Empson, 2013; Wagner,

Núria Planas

Nuria.Planas@uab.cat

1 School of Education, Universitat Autònoma de Barcelona, Campus Bellaterra, EG5, 08193 Cerdanyola del Vallès, Catalonia, Spain

2 Department of Mathematics Education, University of South Africa, Pretoria, Gauteng 0003, South Africa 
2007). Some of these works use the term language as resource in the discussion of multilingual mathematics teaching and learning, in relation to minority languages - the languages that people in a context perceive as such-and in the representation of a sort of ideal that multilingual educational settings should pursue. In this article, I examine a research on multilingual mathematics classrooms and mathematics learning in order to propose a conceptualization of language as resource that captures the possibility of texts to produce newer meanings and situations out of the amount of potentially realizable meanings and situations available in language. In the process, I assume the ontological stance that language and language use are two dimensions of the same phenomenon (Pimm, 2014). Such ontology goes with the socially constituted knowledge of diverse languages - verbal and visual - that people develop as part of their social experience of/in the world (Makoni \& Pennycook, 2005).

The thinking of language as resource in mathematics education research gets inspiration from its original thinking by Ruíz (1984) in language planning research. Ruíz produced the socalled resource orientation to reflect on the placement of heritage and immigrant languages in the U.S.A. as a politically beneficial asset to cultivate. He controversially argued that the recognition of these languages could well serve geopolitical, diplomatic and economic aims due to its implications for resolving conflicts between language groups and cultural communities. From the perspective of mathematics education, the discussion of language as resource incorporates the pedagogic value of language (Planas \& Setati-Phakeng, 2014) in critical ways that respond to views of mathematics teaching and learning that privilege one language of mathematics and one language of instruction (Planas, Morgan, \& Schütte, 2018). The resource metaphor is particularly important in multilingual classrooms due to the numerous studies that continue to report that multilingual learners are somehow "lacking" in language. Throughout two decades of visiting Catalonian schools and mathematics lessons in low-income neighborhoods, I have experienced discourses of "language learners" implying learners of the official language of instruction - not learners of language - produced in opposition to learners who speak Catalan at home (Planas, 2011, 2014). The questions of who is a language learner in the multilingual mathematics classroom and for how long are certainly relevant. However, as Setati (2005) posed it more than a decade ago, most answers still perpetuate the representation of the mathematics learner as someone who is in the process of learning the language of mathematics through the language of instruction regardless of the diverse languages of mathematics and interaction. Embedded discourses remain, linking mathematical ability to the ability to speak specific mathematics in certain languages, which in turn reproduce discourses of people chronically poor in language and mathematics (Jorgensen, 2011).

In the next two sections, I introduce and discuss notions that have created the current need for the theorization of language as resource. The knowledge developed along the study of mathematical lessons frames the revision of mathematics learning as part of what can be achieved, recognized, and reinforced in the discursive realization of multilingual texts in the mathematics classroom. The article continues with the analysis of an instance of group work from a mathematics lesson in Barcelona, the main city of Catalonia, where Catalan is the official language of instruction and some learners are children of Latin American families with stories of immigration and social exclusion. I finish with a notion of language as resource that refers to the potential of language to function in ways that dialectically produce and resolve tensions between languages of learners in cultures of school mathematics and official language of instruction. Throughout the article and similarly to Holland, Lachicotte, Skinner, and Cain (1998) and Holliday (1999), I use the term culture in plural to include (1) emerging norms, practices, and forms of knowledge for representations of the world and people in local sites of 
interaction and (2) more or less reified norms, practices, and forms of knowledge for broader societal representations. As such, language and meaning production in a classroom always reflect and result in different constructions of culture. Small group work, for example, reflects common worldviews shared in the interaction and societal representations of the school institution and of historically acceptable teaching and learning pedagogies. Culture is an active process constructed and operating at different relative levels, from small group to societies with specific language-in-education policies and school mathematics curricula together with many other smaller and larger entities ("small cultures" and "large cultures" in Holliday, 1999) connecting the present and the past. This notion of culture provides an idea of the range of overlapping social realities and groups of people informing language use. Following Halliday (1978, 1985), I particularly use context of culture to mean the uncountable constructions of culture that meet and influence each other in any interaction of any "size." In this way, I emphasize the fact that exclusive sets of norms, practices, and forms of knowledge cannot produce language and meaning in isolation and separately from other constructions of culture.

\section{Social languages, language systems, and the systems of language}

The ontological stance that language implies concrete language use embraces the inseparability of language and discourse. Any instance of language has a discourse origin (any text is a social, cultural, and historical product) and a discourse effect (any text is implicated in the deriving of a discourse). Like Gee (2004a, b), I refer to discourses as relational representations of socially, culturally, and historically influenced ways of interaction that spread within and across languages and move back and forth through culture. The point with a text-written, spoken, or visual - is that what communicates is not a mere formal manifestation of the linguistic code or system that makes sense to those who know the language, but a discursive instantiation that requires the interpretation of the immediate situation and culture. It is in this respect that language and discourse presuppose culture: the context for any instance of language and discourse is the context of culture. This relationship is important for the recognition, in the next section, that mathematics learning occurs as realization of meaning potential embedded in language.

The problematization of language, discourse, and culture, and of the theoretical continuum from one to the other, has led to productive lines of study in mathematics education research. Sociolinguistic theories have framed initial efforts in the understanding of the culturally contextual nature and function of texts and have been decisive in setting a rationale for pursuing a notion of language embracing the notions of discourse and culture in mathematics education. The early reworking of Gee's theory of identity (Gee, 1996) by Setati $(2005,2008)$ is a precedent of the attention to language to indicate the multiple discourses voiced by people in multilingual mathematics teaching and learning. Following the idea of multiliteracies by Gee, Setati considered learners as multi-discoursal people, that is, people involved in a variety of communities with different languages in use for the organization and distribution of access to social goods. All these communities of reference and their related languages work to provide social identity to learners in the processes of learning school mathematics and of acquiring school languages and societal ways that will make them people with particular cultural and social capitals. Research in sociolinguistics under the influence of Bakhtin (1981) has also preceded and prepared adoption in the field of a notion of social language (Barwell, 2014, 2016a, b). Social languages express the forms of language through which people and 
groups can be recognized and linked to specific worldviews in a given situation and context of culture. Such perspective reinforces language as dialogical because it always occurs in conversation with self and others and plural because it always voices (i.e., textually reproduces) multiple discourses and their cultural underpinnings. When we engage in talk, therefore, we navigate within, between, across, and outside discourses to face the challenges embedded in coming to voice - through diverse languages - our worlds while also attempting to view/imagine the worlds of others (Holland et al., 1998).

In Planas (2014), some aspects of Gee's sociolinguistics (Gee, 1996) served to examine how participants in lessons of mathematics draw on their languages to communicate their mathematical thinking. In the analyses of spoken texts, I looked at occurrences and inferred effects of instances of codemixing, codeswitching, and other alternate uses of two or more "labeled" languages (e.g., Catalan, Spanish, and Amazigh) within one sentence or interaction. The awareness of the multiplicity of social languages within any "autonomous" language was already there in the representation of language systems as politically rule-governed. At that time, however, I was not clear about how the distinction between, for example, Catalan and Spanish was contributing to the textual reproduction of wide discourses on linguistic fixity and accuracy. Research certainly voices different discourses depending on whether translanguaging (Smith \& Murillo, 2015) or codeswitching is put to the front. While codeswitching implies the recognition of prescriptive language systems and the assumption that communication neatly breaks into languages, translanguaging refers to what people actually do with language to convey meaning. Instead of signaling the alternation of enclosed language systems, translanguaging sees language as an open broader system that allows combinations of social, cultural, and linguistic codes (Rubinstein-Ávila, Sox, Kaplan, \& McGraw, 2015). The focus is thus on what learners do by means of all their (social) languages and not on how they perform language in normative ways. This also applies to interpret language in situations in which multiple mathematical sign systems, iconic representations of mathematical objects, and narratives of mathematical ideas co-exist (see examples in Moschkovich, Zahner, \& Ball, 2017). As such, translanguaging illuminates the move toward considering language as intertwined and open with a range of options available for participation in specific situations within particular contexts of culture. Taking this view, we inescapably come to the issue of the potential of language to report as well as to influence and develop meaning.

A number of functional theories of language have served to address the potential of language in mathematics education research. The work of Morgan $(2006,2014)$ has particularly contributed to examining the utility of the systemic functional linguistics of Halliday $(1978,1985)$ in the approach to the phenomenon of meaning potential. Halliday ties the possibilities of meaning production to the possibilities available in the systems of language, where form and function play an integral role. This position resonates with the frameworks by Gee and Bakhtin in that language involves the recognition of discourses, but such recognition now relates to the learning of form-function connections. Learners need to use their languages in socially appropriate ways to build meaning, and they learn to do so when dealing with responses to and consequences - perceived or real — of some uses. This is a learning of major importance since it enables learners to influence the immediate situation by grounding on various levels of verbal organization and performance that go beyond concrete vocabulary and specialized notation and even beyond logical sequencing of units (Morgan, 2014). For example, there is some learning needed about how combinations of transitivity processes (material, relational, verbal, mental, existential, or behavioral) function to express the network of possible experiences of the world, some of which may (not) be valued in the cultures of 
school mathematics and language of instruction. Functional plurality is also an object of learning in the use of modality features (e.g., modal verbs and tenses, adverbs, adjectives, personal pronouns, direct and indirect speeches, interjections) concerned with the network of possible social and personal relationships. Formal linguistic options become tools for the functional realization of meaning in ways that satisfy the criteria to be met by speakers in order to become participants of specific communities and groups.

Figure 1 brings together notions discussed for the understanding of language. All social languages have recursive systems of language that play an intricate role in meaning production. Only some of these languages, however, become stated in institutionalized grammars, dictionaries, and other cultural forms of linguistic reification and then largely called language systems. The squares representing these notions in Fig. 1 overlap to indicate the fact that speakers/learners deal at the same time with the articulation of these dimensions of language. For example, performance of grammar and lexical systems of languages overtly valued in the context of culture cannot be isolated from performance of systems of languages with value in the home or the age group. In the multilingual mathematics classroom, thus, language is variably realized within the network of options produced and activated at the intersection of systems of language and social languages; two of which are specifically reified as language systems, the language of mathematics and the language of instruction. This complex network of options remains at the core of language and reveals the dialectical circulation between realizable and realized texts in the context of culture.

\section{Mathematics learning as discursive realization of meaning potential}

In this section, I argue that mathematics learning develops over the course of processes of actualization of meaning potential shaped by language use (and hence by the intertwining of social languages, language systems, and systems of language). While it is not very common to approach mathematics learning in terms of the socially situated actualization of a potential, the issue of the social situatedness of mathematics learning is not new at all. Cobb, Yackel, and Wood (1992) related this learning to the social conditions in a given setting and coined the term mathematics learning opportunities to express the consideration of the social. The experiments that followed aimed to introduce changes in classroom teaching and learning such as small group work and whole-class conversation for the effective communication of mathematical meanings. Saxe (2012) and Saxe et al. (2009) also related mathematics learning to the situated emergence, exploration, and development of mathematical meanings. They produced the metaphor of the travel of ideas to refer to their research into the ways in which mathematical meanings evolve in the public space of lesson discussions. Overall, all these authors brought up the issue of shared meaning, which is still an ongoing debate in mathematics education research (de Freitas, 2016), but not so much the issue of meaning potential.

Fig. 1 Cluster of notions in the understanding of language

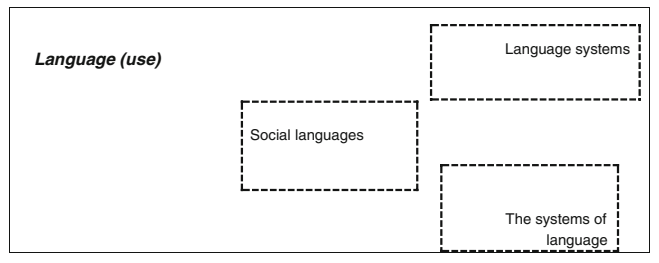


By mathematical meanings, I denote meanings widely established as the substance of what is taught and ought to be learned in cultures of schooling and especially of school mathematics, recurrently shown and invoked as valued institutionalized ends in curriculum, task design and implementation, evaluation, assessment policies, and practices (Barwell, 2014; Morgan, 2006, 2014). The realization of this type of well-determined meanings frames the problematic recognition of learning. When learners participate in the mathematics classroom, they do not do so as ideal voices of either intended or expected institutionalized discourses of schooling and school mathematics. Particularly for classrooms in highly diverse societies with multiple language and cultural groups (Planas \& Setati-Phakeng, 2014), there may be some languages that voice "other" experiences of/in the world and social relationships alongside with languages that relate these experiences and relationships to poorness in language and mathematics. Meaning taken as mathematical and shared is therefore produced in a continuum of shared/ non-shared related options including meaning not shared in the culture but communicated, considered, and appreciated in the immediate situation and vice versa. Drawing on the shared/ non-shared dialectic of meaning production, we can imagine the anticipation and emergence of newer shared meaning in the multilingual mathematics classroom. This dialectic indicates the integration of opposites - e.g., mathematical and not mathematical - and the transformation of meaning oriented by some of the options that the tools of language (Fig. 1) provide.

The multilingual learner of school mathematics is someone with a repertory of meanings, not always created as mathematical and shared and subjected to discourses of language-ineducation that produce the languages of some communities as unfinished and mainly operating at a home level (Planas \& Civil, 2013). Such construction inevitably influences the options made available and produced in language. However, empirically driven evidence of learners drawing on and using their languages and meanings to learn mathematics in the immediateness of classroom situations in cultures of official language of instruction (e.g., Setati, 2005; Planas, 2011; Turner et al., 2013) substantiates the possibility of transforming the very conditions of recognition of meaning as it goes along. Overall, the realization of language as resource for the creation of mathematical meaning requires attention to the context of culture and to the immediate situation in which learners interact with the language of mathematics and the language of instruction. Taking the approach to resource as necessarily involving some resourcing work and purpose (Pepin, Gueudet, \& Trouche, 2013; Remillard, 2005, 2013), Fig. 2 represents language as resource at the crossroads of the generative work that orients the purpose of mathematical meaning making. The four "roads" indicate four major forces in tension in the use of language as resource for mathematics learning in classrooms with cultures of school mathematics and official language of instruction. The position of language as resource in the middle of the crossroad points to the theoretical need to address the inevitable tensions around the discursive instantiation of language in the mathematics classroom. Although such tensions may have a psychological expression (e.g., see the psychological experience of teaching dilemmas by teachers in Adler, 2001), they are primarily framed in this article as features of language (see the Bakhtinian discussion of language forces in Barwell, 2014). Hence, I interpret mathematics learning in relation to meaning potential and language, but also and importantly as occurring in a constant tension between what is already given by the force of the context of culture and the process of creating newer meanings that may become recognized by the force of the immediate situation. Bakhtin (1981) provides a lens through which to view tensions in relation to dialectical oppositions that need not necessarily be resolved and that can be or not noticeable by participants and at times cause direct reaction. In line with this view, Fig. 2 emphasizes two major interrelated tensions 
Fig. 2 Cluster of notions in the understanding of language as resource

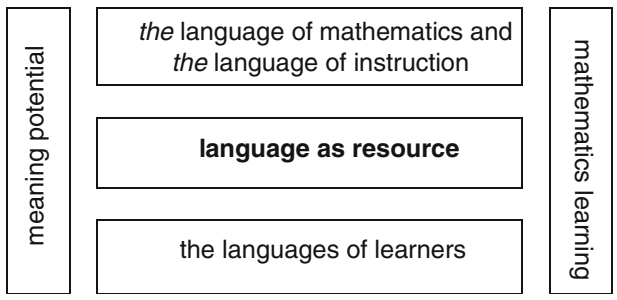

between competing forces, each promoting specific languages and meanings at the expense of others. On the one hand, the totality of languages of mathematics, of the home, of the community, of the age group, etc. tensionally interacts with two dominant languages in the context of culture and their underlying discourses (vertical axis). On the other, the totality of meanings provided by the context of culture tensionally interacts with the production of newer meanings that can be viewed as mathematics learning in the immediacy of the situation (horizontal axis). These tensions exist in dialectical circulation; they are not linear or directional and do not represent progression relative to any kind of privileged language or meaning. When looking at language in a moment of interaction, however, the fiction of temporary displacement of some forces in tension may be created, and consequently, the experience of tensions reduced.

Although any text is always limited in terms of the actualization of some meanings over others, the potential inherent to language and rooted in the immediateness of the situation makes newer texts possible. Before further addressing the dialectical nature embedded in the theorization of language as resource, in the next section, I explore an instance of group work with two languages accepted as natural and distinct in the context of culture, one of which is the official language of instruction. Following the interpretation of Fig. 2 and the proposed notion of language as resource, the approach to data analysis seeks out the discursive instantiation of tensions. Such an approach attempts to illustrate the possibilities for language to reduce forces that do not primarily privilege the production of shared meaning for mathematics learning.

\section{Language and mathematics learning in student group work}

The educational politics and discourses of affirmation of cultural heritage through language protection is a significant context of culture in Catalonia. Despite a majority of political forces supporting the policy of language-in-education, specific communities in the state exercise pressure for recovering the status of Spanish_vindicated as a "national language" - in the region. Additionally, more and more private schools have started to use English — vindicated as a "world language" - as language of instruction for mathematics and science. The group of the example belongs to an eighth grade classroom of a public school in a low-income area of Barcelona. The teacher is a Catalan-dominant speaker who occasionally uses a variety of Castilian Spanish in her lessons. Fourteen students are children from Colombian, Ecuadorean, and Peruvian families, nine of whom were raised abroad; five are children of Castilian Spanish-dominant families, two of whom were raised in Castilian-speaking regions of Spain, and four are Catalan-dominant speakers raised in Barcelona. The learners raised abroad were designated on their arrival as "latecomers" and attended the so-called "special lessons" during school hours to accelerate their learning of the language of instruction. It is important to note that linguistic varieties of Colombian, Ecuadorean, Peruvian, and Castilian Spanish and 
combinations of these are not typical of the Spanish spoken by people raised in the Catalanspeaking region of the state. There are differences in sounds of letters (e.g., grave and acute vowels) and conjugation of verbs (e.g., continuous and simple tenses). Those who claim "Catalan nativeness" tend to disparage Catalan spoken with sounds, conjugations, words, and phrases from these other languages (Pujolar, 2010).

Two students of the group, Ada and Leo, were "latecomers" for 1 school year on their arrival in sixth grade. They were born and raised in Peru and said to speak Spanish at home. The other learners of the group, Maria and Ton, who were born in Barcelona, had always attended regular lessons and said to speak Catalan at home. In the lesson of group work, the task was about the printed pages in a book:

A book has 89 pages, but the page numbers are printed incorrectly. Every third page number has been omitted, so that the pages are numbered $1,2,4,5,7,8 \ldots$ and so on. What is the number on the last printed page?

The selected instance starts with Maria sharing her procedure with Leo, Ada, and Ton by counting one by one the first pages of the book, which is problematic as soon as the number of pages increases. The factorization of 88 introduced by Leo functions as a pivotal idea in the exploration of an algebraic pattern:

1. Maria: $U i$ dos, quatre $i$ cinc, set $i$ vuit, deu $i$ onze... fins cent trenta-tres [One and two, four and five, seven and eight, ten and eleven... up to one hundred and thirty-three.]

2. Leo: ;Muy largo! [Very long!]

3. Maria: Cap problema, no son mil páginas. [No worries, it is not one thousand pages.]

4. Leo: Agafem les pàgines que falten. [We take the missing pages.]

5. Maria: [On the worksheet, "ochenta-y-nueve," number word for 89.] Què és això? Uf! Fatal! Has preguntat a l'Ada, oi? [What is this? Ugh! Pretty bad! You asked Ada, eh?]

6. Ton: Què més et dóna? El problema és el que importa. [Why do you care? The problem is what matters.]

7. Leo: Cada dos números, falta un. Piensa mejor ochenta y ocho. Pasa cuarenta y cuatro veces. No hi ha quaranta-quatre números. [Every two numbers, one is missing. You would better think eighty-eight. It happens forty-four times. There are not forty-four numbers.]

8. Ton: Però aquest quaranta-quatre, d'on surt? [But this forty-four, where does it come from?]

9. Leo: Cada dos, uno fuera. De cuarenta y cuatro por dos, ochenta y ocho. I sumes els que no es fan servir. Cent trenta-tres. [Every two, one out. From forty-four times two, eightyeight. And you add on what is not used. One hundred and thirty-three.]

10. Ada: Ahora con el llibre de llegir, ciento dos páginas. [Now with the reading book, one hundred and two pages.]

11. Maria: Una meitat és cinquanta-u $i$ ho sumes. [One half is fifty-one and you add it up.]

12. Leo: Un llibre de ciento dos no és com aquest... És com de sis pàgines, o de vuit. No és tres, o cinc, o set, o nou. [A book of one hundred and two is not like this... It is like the one with six pages, or eight. It is not like three, or five, or seven, or nine.]

13. Ada: ¿Cuáles números son como ochenta y nueve? [Which numbers are like eighty-nine?]

14. Ton: Dieu cuáles números, eh? [You say which numbers, eh?]

15. Ada: Diem cuáles son como ochenta y nueve. Cuáles son como. No vull dir cuáles son ni cuántos son. No más ejemplos, por favor. [We say which are like eighty-nine. Which are like. I do not mean which are or how many are. No more examples, please.] 
16. Leo: Vale, mira. Con todos los pares, como ochenta y ocho primero sacas uno, perquè no arribes a múltiples de tres. [Okay, look. With all even numbers like eighty-eight, you first take one out, because you do not reach multiples of three.]

17. Maria: Vuitanta-nou és quaranta-quatre per dos més u i vuitanta-vuit és quaranta-quatre per dos. Busques sempre cada dos [Eighty-nine is two times forty-four plus one, and eighty-eight is two times forty-four. You always look for every two.]

The analysis that follows examines explicit tensions involving some languages of learners - as substantially different to the official language of instruction - and some of the emerging mathematical meanings - as substantially different to those embedded in the culture of school mathematics. I intend to show language uses with influence on (i) the communication of tensions around the languages of Leo and Ada and (ii) the dealing with these tensions in ways that keep the production of mathematical meaning. The transcription into English plays a role and represents a challenge given the linguistic particularities of Catalan and Spanish in the original piece with no exact straightforward inter-linguistic correspondences. The interpretation of two particularities when I re-encoded data in the target language needs some explanation. Normative English grammar generally requires putting something in the subject position in verbal phrases, but this is not the case in the majority of verbal phrases in the original data. "Dieu cuáles números" [turn 14] reads well without the subject position because "you" can unequivocally be inferred from the conjugated form of the verb. Even so, there is still the possibility in Catalan and Spanish normative grammars to put something in the subject position and use redundancy to express emphasis on the actor. The fact that such emphasis is not grammatically marked in the exemplified instance does not impede the attribution in language to distinct memberships. Ton could have avoided the conjugated form with a nonverbal phrase like "Cuáles números." This is an important linguistic feature to take into account when reading the analysis. The second linguistic consideration is the decisive relevance of word order to signal additional emphasis on modal forms-e.g., imperative, exclamative - in normative Catalan grammar.

\subsection{Communication of tensions in language}

Learners index numerous tensions concerning some of the languages made visible in the interaction. There are rather subtle tensions that, for example, have to do with marked pronunciations for the same term ("quaranta," said by Leo [7] and then by Ton [8] and Maria [17]) and the implicit suggestion of not sounding right. I concentrate on two of the tensions that become visible during the production of arithmetical meanings related to iconic and symbolic shared ways of considering the numerical answer to the problem: 133 as the end of an ordered sequence starting with one and following with non-multiples of three, and 133 as the result of the operation $(2 \times 44+1)+44$. Maria writes and counts all page numbers except for the multiples of three [1]. Leo mentions the factorization $88=2 \times 44$ [4], the account for 89 as $2 \times 44+1$ [7], and the equivalence $89+44=133$ [9] for the connection of the 44 page numbers missing with the printed number on the last page. He emphasizes the pattern involved in the resolution of the problem as well as the strategic thinking of adding the omitted numbers and reaching a pattern that serves for a book with any page number. Progress toward a more general reasoning needs to distinguish odd and even numbers. If $n$ stands for the pages in the book, the number of the last printed page is $n+(n-1) 2$ for an odd $n$, and $n+\left(\begin{array}{ll}n & 2\end{array}\right)-1$ for an even $n$. Group work does not produce a piecewise 
algebraic pattern, but separates odds from evens [12, 16-17]. The language that follows from 10 extends the problem to books with various page numbers. An enumeration functions to group evens with 89 and odds with 102 .

In this situation of negotiation of some arithmetical meanings as shared, we find tensions regarding the languages of Leo and Ada. Exclamative and interrogative modes and interjections point to the language of Leo as a source of conflict in 5. "What is this? Ugh! Pretty bad!" produces the meaning of something wrongly written on the worksheet and has the effect to interrupt an explanation. Maria communicates the inappropriateness of the language of Leo when writing the number word "ochenta-y-nueve." The account for 89 juxtaposes three Spanish words with the Catalan grammar rule for hyphened numerals: in normative Catalan, eighty-nine would be "vuitanta-nou," while in normative Spanish, it would be "ochenta y nueve." "You asked Ada, eh?" suggests who may be responsible for that language, with an intonation that rather alludes to a concern with the collaboration between two learners who may share an inadequate language. The interjection and intonation in 14 "You say which numbers, eh?" points to the language of Ada in 13 as another source of conflict. Ton refers to the word "cuáles" that stands for the pronoun "which" by means of a plural "you" verbally conjugated so that the language of a group is invoked. Catalan-dominant speakers would typically say "qué" in their use of normative Castilian Spanish. The concern about "cuáles" interrupts a question of relevance for continuing the task. This is not a situation where learners meet for the first time. They know each other well and share knowledge concerning who attended special lessons and what this may mean. Underlying both tensions, therefore, there may be several discourses at play circulating in the context of culture, some of which are about "latecomers," nativeness, and language of instruction.

The emergence of tensions occurs simultaneously with several instances of translanguaging - between Catalan and Spanish linguistic features, pronunciations, and phrases - that seem to arise naturally. Despite discourses of official language of instruction in the context of culture, there is no explicit allusion to learners in the group "lacking" $a$ language. The situation, however, does not escape the realization of a normative view on some languages and the assumption in the first instance of the idea of an appropriate language to speak mathematics. The voicing of discourses of some learners as language learners is here located as originating in the choice of inappropriate words. One of the words stands for a numeral, but normativity does not appear specifically related to discourses about the language of mathematics. In fact, we can denote translanguaging related to a plurality of narratives for the explanation of mathematical ideas (Morgan, 2006, 2014; Moschkovich et al., 2017). There are more or less formal expressions of school mathematics with different levels of pronominalization (e.g., "even numbers" [16] versus "one is missing" [7]). Some learners use nominal phrases with a focus on exposition and qualification of products (e.g., "very long!" [2]), mainly consisting of enumeration of numbers (e.g., 1). This makes a contrast with the languages of mathematics of those who talk through verbal phrases in imperfective present tense in the original piece and thus communicate thinking processes (e.g., "we take the missing pages" [4]). All these languages of mathematics as well as Catalan and Spanish linguistic hybrid features suggest a relaxed construction of the language to speak mathematics alongside with the textual reproduction of discourses of linguistic accuracy and of unacceptability of certain hybridizations of language. More generally, the resulting culture of promoting variable attention to some forces in tension over others points to the role of the immediate situation in producing space for learners to find uses of language in between competing discourses. 


\subsection{Resolution of tensions in language}

Language is decisive in the communication of tensions and in the instantiation of changes in tensions over time. Tensions change to reveal newer end positions, produced as more or less different as language does. Resolution, thus, does not imply that tensions disappear, but that their actual expression in language allows the continuity of processes aimed at the negotiation of shared meaning. In the example, while translanguaging provides the space for building meaning at the intersection of diverse languages, grammar produces and reproduces the focus of talk. A number of phrases facilitate the moves away from the attention to linguistic features of the languages of Leo and Ada to the attention to narratives of mathematical ideas. Material, mental, and existential phrases contribute to showing and acknowledging what learners have done and achieved in their thinking. Some examples are "you add on what is not used" [9], "you first take one out" [16], "you would better think eighty-eight" [7], "I do not mean which or how many are" [15], "every two numbers, one is missing" [7], and "there are not forty-four times" [7]. Relational phrases are also used widely in describing numerical properties (e.g., "one half is fifty-one" [11]) and decomposition strategies by informing (e.g., "eighty-eight is two times forty-four" [17]) and questioning (e.g., "which numbers are like eighty-of nine?" [13]). All these phrases strengthen the concretion of abstract relationships within number sets (e.g., evens and odds) and mathematical facts (e.g., recursivity). In this way, language evolves from enumeration and exemplification of numbers and procedures to explanation and discussion of patterns. Engagement in the production of meanings as mathematical and shared is particularly visible in the behavioral and verbal responses to the concerns about "ochenta-ynueve" and "cuáles."

When Ton responds to the implicit mention of Leo and Ada as poor users (writers) of language, there is a fundamental phrase in the form of "why do you care?" [6]. Either the question alludes to asking Ada, to the writing of "ochenta-y-nueve" or to anything else, it has the potential effect of appealing to processes of sensing, feeling, and behaving for appreciation of alternative options and for resistance to change in focus. The relational attribution in "The problem is what matters" strengthens the actualization of this potential and functions to center the discussion back on the resolution of the task. Regarding the use of "cuáles" by Ada, most responses are verbal (you say [14]/we say [15]/I do not mean [15]) and behavioral (exclamative interjection [14]/direct enunciative [15]). Action as a member of a language group and resistance to any undermining of this membership is encoded. While the you-we-I conjugated pronouns and changes in intonation [15] grammatically shape this space of resistance, the lexical differentiation between "which are like," "which are," and "how many are" [15], together with the imperative "No more examples, please" [15], reproduces the distinction between enumeration of numbers and explanation of facts underlying patterns. The situation moves into language that functions to put at the front meanings produced as shared and acceptable so that "ochenta-y-nueve" and "cuáles" become unnoticed. The overcoming of tensions is relative since learners do not overtly deal with and resolve the basic long-standing conflict, rooted in the context of culture and of learners of mathematics with inadequate languages of the home and the community.

This example serves to explain that language as resource is not about the unproblematic functioning of language as producer of meaning taken as mathematical and shared. On the one hand, language contributes to the realization of normative meanings in the culture of schooling and school mathematics alongside with normative meanings that textually reproduce discourses of linguistic fixity and accuracy. On the other hand, language enables learners to 
influence the process from potential to actual meaning through their socially constituted knowledge of the languages and speakers in the interaction. In this sense, language is a resource for the production of mathematical meaning and for the relocation of culture in the immediate situation of group work. Since meaning is not a direct result of form and function, the use of language in these processes of production and relocation is not a simple matter of choice either. Choice is certainly necessary in the configuration of texts but this choice in practice must happen among a range of options. Learners act within the possibilities framed by grammars and discourses likely to be voiced and forced on texts about the value of the language of mathematics and the language of instruction but also about the value of the "other" languages and their speakers. Recognizing these boundaries and seeking to understand the dialectics underlying the realization of mathematics learning, we can think of a certain bounded choice on the side of learners. Maria, for example, has the choice to use phrases with no subject ("No worries" [3]) in contrast to phrases with subject ("You have asked Ada, eh?" [5]) to convey in this way the language of a learner. Moreover, she has the choice to voice discourses of linguistic accuracy and take meanings introduced by Ton as an opportunity to move into discourses of school arithmetic. Choice changes as boundaries and opportunities in the context of culture and the social situation change and hence as language changes.

\section{Theorization and dialectics of language as resource}

I started the article claiming that the thinking of language as resource in mathematics education research has been more metaphorical than conceptual and, as such, the term has been treated imprecisely for more than a decade now. Today, the use of the idea in the field is not emergent anymore and requires conceptualization. Throughout this article, I have exposed the grounds and reasons of the theorization of language as resource. I have highlighted the dialectical tensions and discursive instantiations in language use, with the attention to potential/realized and shared/non-shared meaning. From here, I have argued and exemplified that in language, there is always the potential for shared meaning as well as the potential for reconstructing texts, in the immediacy of the interaction and within a range of options given by the context of culture. The dialectics discussed are not exhaustive of the diverse dialectics in the functioning of language in communication (see, e.g., Barwell, 2016a), but they suffice to facilitate newer ways of thinking about language as resource. Language emerges as a shifting resource, mutually co-producing learning of school mathematics and of broader societal discourses and cultures. That is to say that we cannot theoretically and practically separate languages for mathematics learning from other languages, and privilege the former in the view of what is involved in mathematics learning. Such separation is retained into binary conceptions that consider the language of mathematics and the language of instruction at the same time and in isolated differentiation. Far from this thinking, I have indicated that all languages are of reciprocal influence, they are all necessary to each other and circulate in meaning production. In the example, we cannot understand language as resource for mathematics learning without arguing the relevance of "You say which numbers, eh?," and its potential effect in the realization of meaning taken as mathematical and shared. Leo, Ada, Maria, and Ton perform grammars that voice and resist discourses of linguistic normativity in the moves back and forth from preserving and revising arithmetic languages of enumeration, exemplification, and explanation and languages in between. The four of them use language in open-ended ways that resist change in focus and configure newer texts, while also supporting continuity of texts 
brought up by others in the group. From this perspective, then, the ideal to be pursued is not an immediate "autonomous" language of the classroom that apparently avoids interferences from the context of culture, but rather a language that functions to resolve tensions between contrasting discourses with potential effect on the production of what is valued and why in the mathematics classroom.

There remains a challenge to show how multiple dialectics intersect and are inescapably involved in the communication and resolution of tensions regarding the languages of some learners. This in turn raises questions about the constraints of theorizing language as resource without profoundly addressing the range, diversity, and relationality of dialectics in the process toward a dialectical and discursive approach. The understanding of language as resource is not reducible to a few dialectics but the limited discussion of some of them may be enough to emphasize the complexity of heterogeneous, multiple, and interchangeable processes, relationships, and flows contained within language and mathematics learning. Even if the attention to the individual/social dialectic, for example, has been tacit in this article, I have provided frameworks that interchangeably privilege social structure and individual action (e.g., Barwell, 2014; Morgan, 2006; Smith \& Murillo, 2015). Translanguaging competes with politics of language and language diversity that configure the situation in ways that create higher demands on some learners to show improved performance of acceptable language use. Under these frameworks, we can read Leo's participation and Ton's creative response in the form of "The problem is what matters" and assume that they are both clear of the relevance given in school and society to linguistically accurate language. When we refer to the language of Ada in the example, we can read her position dialectically, located at the interplay of the individual and the social.

Past and present constitute another fundamental dialectic in the thinking of language as resource. Prior experiences - real or imagined — of meaning transformation shape the specific meanings made visible and communicated as significant in the example. The lack of boundaries between past and present particularly relates to the interpretation of the situation in the context of culture in Halliday $(1978,1985)$. Tensions regarding the languages of some learners do not necessarily persist as extremes if participants have come to learn the network of options available so that they can draw on this learning to imagine realizable worlds (Holland et al., 1998). Maria, Ton, Leo, and Ada have experienced, for example, the existence of special lessons and differentiated curriculum for "latecomers" at school. Past is in their "reading" of group work and becomes present in the immediate situation where newer meanings for/about the future can be reproduced regardless of segregation policies and practices of special lessons for "latecomers." At this point, it is crucial to reflect on the past/present experiences that can help learners conceiving of situations different from those presented as inevitable by the context of culture and supported by exclusionary discourses of school mathematics and official language of instruction. Although the theorization undertaken suggests caution in either celebrating or dismissing the creative power of language, it contemplates language as an object of learning so that some obstacles to creativity are avoidable. Practitioners have a significant role to play in opening up transformative visions of language in classroom. Researchers also have a role by means of re-shaping the representation of language and uncovering cultural processes of reification of certain languages and meanings over/against others. By addressing the tensions involved in language, meaning, and learning, practitioners and researchers may move beyond polarized views of language use to represent in between balanced positions. More than an ideal entity, language is the place to imagine and make possible equitable and quality ways of mathematics learning and teaching. 
Funding information This study is funded by Catalan Institute of Advanced Studies and Research-ICREA; EDU2015-65378-P, MINECO/FEDER.

Open Access This article is distributed under the terms of the Creative Commons Attribution 4.0 International License (http://creativecommons.org/licenses/by/4.0/), which permits unrestricted use, distribution, and reproduction in any medium, provided you give appropriate credit to the original author(s) and the source, provide a link to the Creative Commons license, and indicate if changes were made.

\section{References}

Adler, J. (2001). Teaching mathematics in multilingual classrooms. Dordrecht: Kluwer.

Bakhtin, M. M. (1981). In C. Emerson \& M. Holquist (Eds.), The dialogic imagination: Four essays. Austin: University of Texas Press.

Barwell, R. (2014). Centripetal and centrifugal language forces in one elementary school second language mathematics classroom. ZDM, 46(6), 911-922.

Barwell, R. (2016a). Formal and informal mathematical discourses: Bakhtin and Vygotsky, dialogue and dialectic. Educational Studies in Mathematics, 92, 331-345.

Barwell, R. (2016b). Mathematics education, language and superdiversity. In A. Halai \& P. Clarkson (Eds.), Teaching and learning mathematics in multilingual classrooms. Issues for policy, practice and teacher education (pp. 25-39). Rotterdam: Sense Publishers.

Barwell, R., Chapsam, L., Nkambule, T., \& Phakeng, M. S. (2016). Tensions in teaching mathematics in contexts of language diversity. In R. Barwell, P. Clarkson, A. Halai, M. Kazima, J. Moschkovich, et al. (Eds.), Mathematics education and language diversity. The 21st ICMI Study (pp. 175-192). New York: Springer.

Cobb, P., Yackel, E., \& Wood, T. (1992). Interaction and learning in mathematics classroom situations. Educational Studies in Mathematics, 23, 99-122.

De Freitas, E. (2016). Material encounters and media events: What kind of mathematics can a body do? Educational Studies in Mathematics, 91, 185-202.

Ellerton, N. F., \& Clarkson, P. C. (1996). Language factors in mathematics teaching and learning. In A. J. Bishop, K. Clements, C. Keitel, J. Kilpatrick, \& C. Laborde (Eds.), International handbook of mathematical education (pp. 987-1033). New York: Springer.

Gee, J. P. (1996). Social linguistics and literacies: Ideology in discourses. New York: Routledge.

Gee, J. P. (2004a). Learning language as a matter of learning social languages within discourses. In M. R. Hawkins (Ed.), Language learning and teacher education: A sociocultural approach (pp. 13-31). Clevedon: Multilingual Matters.

Gee, J. P. (2004b). New times and new literacies: Themes for a changing world. In A. F. Ball \& S. Warshauer Freedman (Eds.), Bakhtinian perspectives on language, literacy, and learning (pp. 279-306). Cambridge: Cambridge University Press.

Halliday, M. A. K. (1978). Language as social semiotic: The social interpretation of language and meaning. London: Edward Arnold.

Halliday, M. A. K. (1985). An introduction to functional grammar. London: Edward Arnold.

Holland, D. C., Lachicotte, W., Skinner, D., \& Cain, C. (1998). Identity and agency in cultural worlds. Cambridge: Harvard University Press.

Holliday, A. R. (1999). Small cultures. Applied Linguistics, 20(2), 237-264.

Jorgensen, R. (2011). Language, culture and learning mathematics: A Bourdieuian analysis of indigenous learning. In C. Wyatt-Smith, J. Elkins, \& S. Gunn (Eds.), Multiple perspectives on difficulties in learning literacy and numeracy (pp. 315-329). New York: Springer.

Makoni, S., \& Pennycook, A. (2005). Disinventing and (re)constituting languages. Critical Inquiry in Language Studies: An International Journal, 2(3), 137-156.

Morgan, C. (2006). What does social semiotics have to offer mathematics education research? Educational Studies in Mathematics, 61, 219-245.

Morgan, C. (2014). Understanding practices in mathematics education: Structure and text. Educational Studies in Mathematics, 87, 129-143.

Moschkovich, J., Zahner, W., \& Ball, T. (2017). Reading graphs of motion: How multiple textual resources mediate student interpretations of horizontal segments. In J. Langman \& H. Hansen-Thomas (Eds.), Discourse analytic perspectives on STEM education (pp. 31-51). New York: Springer.

Pepin, B., Gueudet, G., \& Trouche, L. (2013). Re-sourcing teachers' work and interactions: A collective perspective on resources, their use and transformation. ZDM, 45(7), 929-943. 
Pimm, D. (2014). Authority, explanation, contention and register: Language data and the surface search for essence. ZDM, 46(6), 967-976.

Planas, N. (2011). Language identities in students' writings about group work in their mathematics classroom. Language and Education, 25(2), 129-146.

Planas, N. (2014). One speaker, two languages: Learning opportunities in the mathematics classroom. Educational Studies in Mathematics, 87, 51-66.

Planas, N., \& Civil, M. (2013). Language-as-resource and language-as-political: Tensions in the bilingual mathematics classroom. Mathematics Education Research Journal, 25(3), 361-378.

Planas, N., Morgan, C., \& Schütte, M. (2018). Mathematics education and language. Lessons from two decades of research. In T. Dreyfus, M. Artigue, D. Potari, S. Prediger, \& K. Ruthven (Eds.), Developing research in mathematics education. Twenty years of communication, cooperation and collaboration in Europe (pp. 196210). London: Routledge.

Planas, N., \& Setati, M. (2009). Bilingual students using their languages in the learning of mathematics. Mathematics Education Research Journal, 21(3), 36-59.

Planas, N., \& Setati-Phakeng, M. (2014). On the process of gaining language as a resource in mathematics education. $Z D M, 46(6), 883-893$.

Pujolar, J. (2010). Immigration and language education in Catalonia: Between national and social agendas. Linguistics and Education, 21(3), 229-243.

Remillard, J. T. (2005). Examining key concepts in research on teachers' use of mathematics curricula. Review of Educational Research, 75(2), 211-246.

Remillard, J. T. (2013). Examining resources and re-sourcing as insight into teaching. ZDM, 45(7), $925-927$.

Rubinstein-Ávila, E., Sox, A. A., Kaplan, S., \& McGraw, R. (2015). Does biliteracy + mathematical discourse = binumerate development? Language use in a middle school dual-language mathematics classroom. Urban Education, 50(8), 899-937.

Ruíz, R. (1984). Orientations in language planning. NABE Journal, 8(2), 15-34.

Saxe, G. B. (2012). Cultural development of mathematical ideas: Papua New Guinea studies. New York: Cambridge University Press.

Saxe, G. B., Gearhart, M., Shaughnessy, M., Earnest, D., Cremer, S., Sitabkhan, Y., ... Young, A. (2009). A methodological framework and empirical techniques for studying the travel of ideas in classroom communities. In B. Schwarz, T. Dreyfus, \& R. Hershkowitz (Eds.), Transformation of knowledge through classroom interaction (pp. 203-222). London: Routledge.

Setati, M. (2005). Teaching mathematics in a primary multilingual classroom. Journal for Research in Mathematics Education, 36(5), 447-466.

Setati, M. (2008). Access to mathematics versus access to the language of power: The struggle in multilingual mathematics classrooms. South African Journal of Education, 28(1), 103-116.

Smith, P. H., \& Murillo, L. A. (2015). Theorizing translanguaging and multilingual literacies through human capital theory. International Multilingual Research Journal, 9(1), 59-73.

Turner, E., Domínguez, H., Maldonado, L., \& Empson, S. (2013). English learners' participation in mathematical discussion: Shifting positionings and dynamic identities. Journal for Research in Mathematics Education, 44(1), 199-234.

Wagner, D. (2007). Students' critical awareness of voice and agency in mathematics classroom discourse. Mathematical Thinking and Learning, 9(1), 31-50. 